\title{
WestVirginiaUniversity
}

THE RESEARCH REPOSITORY @ WVU

Graduate Theses, Dissertations, and Problem Reports

2018

\section{Automotive Crisis: Volkswagen's Emissions Scandal \& Response Strategies.}

\author{
Kelsey Plute
}

Follow this and additional works at: https://researchrepository.wvu.edu/etd

\section{Recommended Citation}

Plute, Kelsey, "Automotive Crisis: Volkswagen's Emissions Scandal \& Response Strategies." (2018). Graduate Theses, Dissertations, and Problem Reports. 8204.

https://researchrepository.wvu.edu/etd/8204

This Thesis is protected by copyright and/or related rights. It has been brought to you by the The Research Repository @ WVU with permission from the rights-holder(s). You are free to use this Thesis in any way that is permitted by the copyright and related rights legislation that applies to your use. For other uses you must obtain permission from the rights-holder(s) directly, unless additional rights are indicated by a Creative Commons license in the record and/ or on the work itself. This Thesis has been accepted for inclusion in WVU Graduate Theses, Dissertations, and Problem Reports collection by an authorized administrator of The Research Repository @ WVU. For more information, please contact researchrepository@mail.wvu.edu. 


\title{
Automotive Crisis: Volkswagen's Emissions Scandal \& Response Strategies
}

\author{
Kelsey Plute
}

Thesis submitted to the Reed College of Media at West Virginia University in partial fulfillment of the requirements for the degree of Master of Science in Journalism

Diana Martinelli, Ph.D., Chair

Elizabeth Oppe, Ph.D.

Catherine Mezera, M.S.

Michael Walsh, Ph.D.

Department of Journalism

Morgantown, West Virginia 2018

Keywords: Crisis Response, Communication Strategies, Automotive Crisis, Volkswagen Emissions Scandal, SCCT, CRM

Copyright 2018 Kelsey Plute 


\begin{abstract}
Automotive Crisis: Volkswagen's Emissions Scandal \& Response Strategies
\end{abstract}

Kelsey Plute

The purpose of this study is to explore the use of crisis communication strategies (i.e. Coomb's Situational Crisis Communication Theory and Bradford \& Garrett's Communicative Response Model) by examining Volkswagen's key messages in U.S. commercial ad campaigns, individual vehicle commercials, and print ads before, during and after the emissions scandal. The content analysis also identified these specific crisis response strategies in the company's 2015 through 2018 annual reports, press releases and letters to the company shareholders. 


\section{Table of Contents}

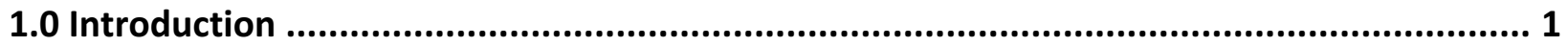

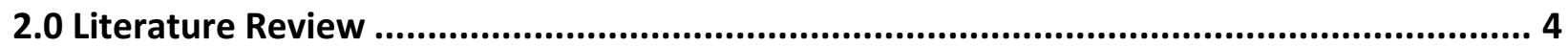

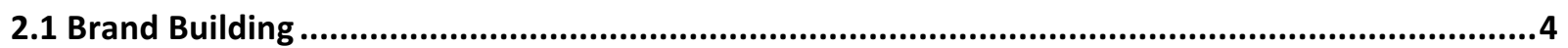

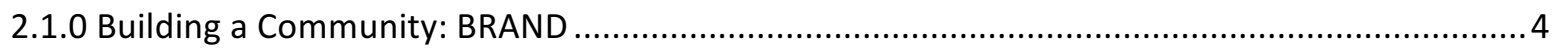

2.1.1 When Good Brands Go BAD .......................................................................................

2.2 Consumer Behavior and Advertising ......................................................................................6

2.2.0 Consumer Purchasing Decisions ...................................................................................

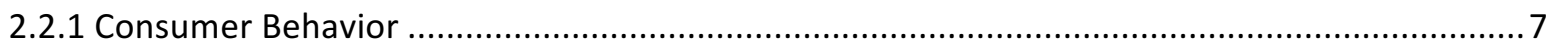

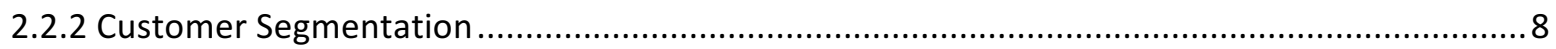

2.2.3 Marketing Gurus Know Their Target Audience .................................................................. 10

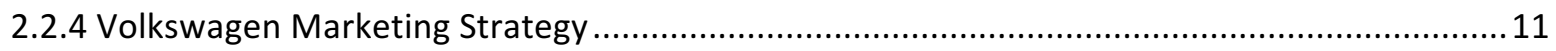

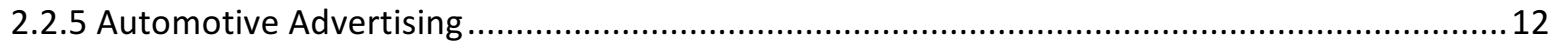

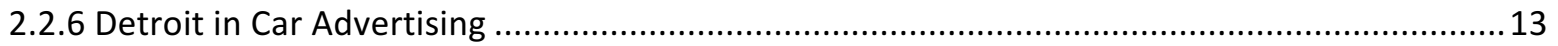

2.2.7 "Do Good" Business ................................................................................................... 14

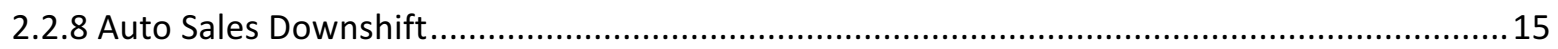

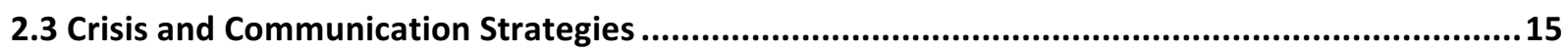

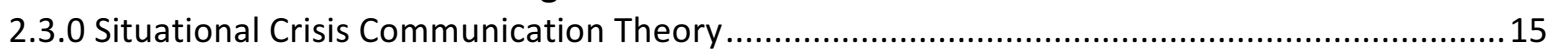

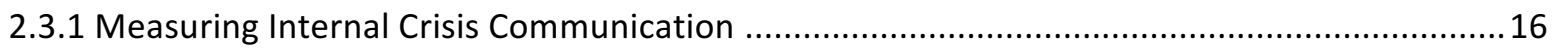

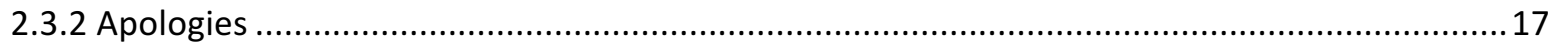

2.3.3 Overview of Challenges Facing Collective Apologies ...........................................................18

2.3.4 Crisis Situations, Communication Strategies, and Media Coverage .......................................19

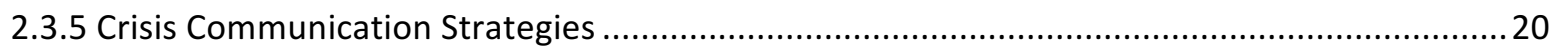

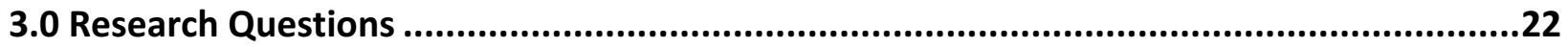

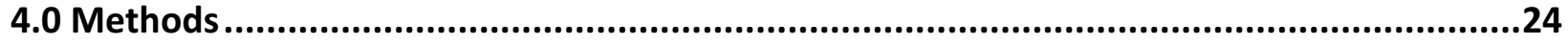

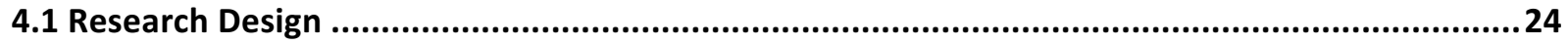

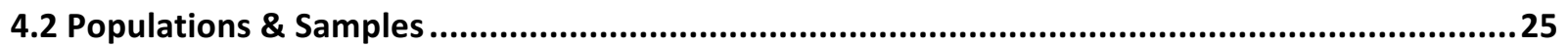

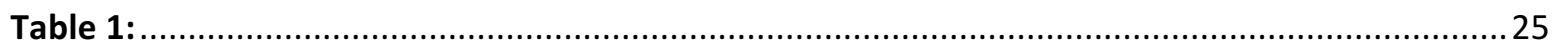

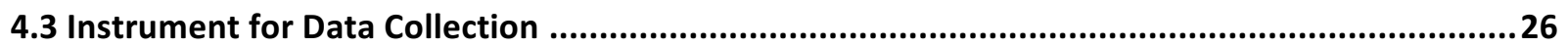

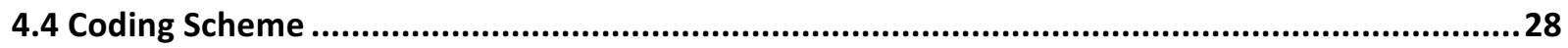

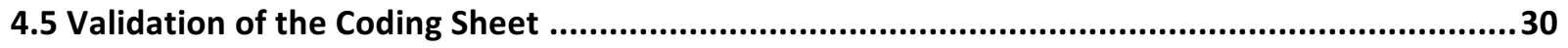

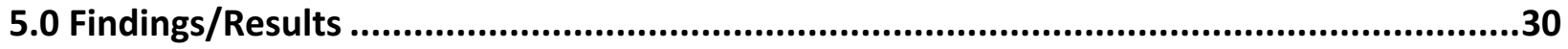

Table 2:

Table 3:

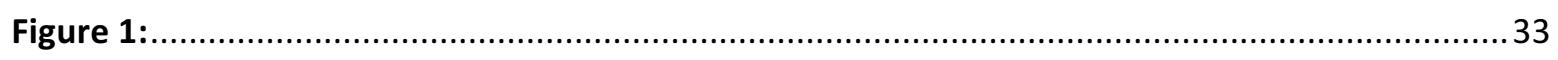

Graph 1:

Figure 2:

Figure 3:

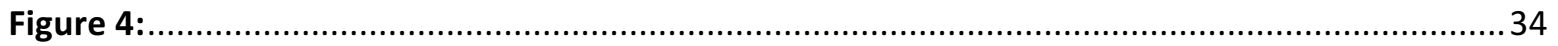


Table 4:

Table 5:

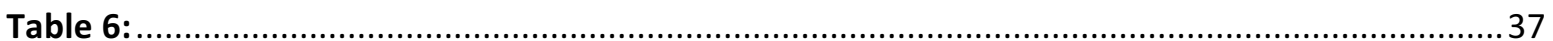

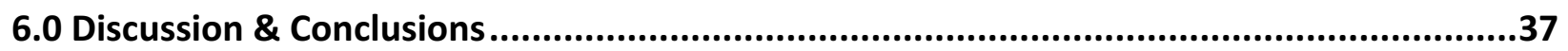

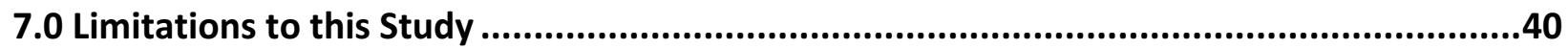

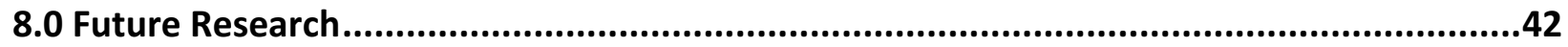

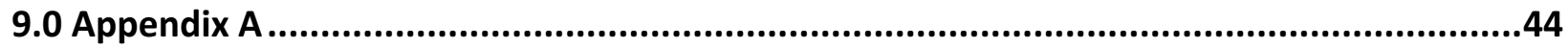

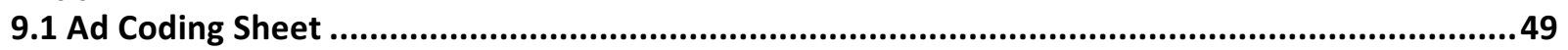

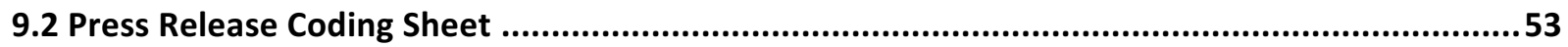

9.3 Shareholder Letter Coding Sheet ..............................................................................................54

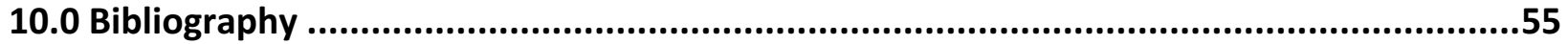




\subsection{Introduction}

In September 2015, the Volkswagen diesel emissions scandal broke with startling claims that the car company was tampering with vehicle emission results. Volkswagen, a German-made brand that means "The Peoples Car," installed emissions software called a "defeat device" in more than a half-million diesel cars in the United States and approximately 10.5 million more vehicles worldwide. The defeat device calibrated false data about the emissions that were being released from each vehicle (Gibney, 2018). Therefore, the VW diesel vehicles were polluting the air 50\% more than the company advertised in such advertisements as "Old Wives Talk Dirty" (Old Wives, 2015).

Volkswagen is one of twelve brands within the Volkswagen Group — the world's largest automaker (Money Talk, 2017)—which also includes Audi, SEAT, Bentley, Bugatti, Lamborghini, Ducati, Commercial Vehicles, Scania, Skoda, Porsche and MAN. Since the Volkswagen emissions scandal erupted, there have been concerns about how the company handled this situation from a public relations and crisis communications perspective, which could possibly extend beyond the VW brand to affect its other brands as well. The documentary series Dirty Money created an episode, "Hard NOx," based on the crisis and provided evidence and police recordings with Volkswagen executives (Gibney, 2018). The executives tried hiding and denying the scandal for months until the Federal Bureau of Investigation (FBI) threatened to shut down Volkswagen factory production in America. Media coverage on the scandal created negative publicity over a long period of time. In 2017, six top executives were convicted and sentenced to prison (Gibney, 2018).

Today's federally mandated reduction of greenhouse emissions in the U.S., with phase one regulations stretching over the years 2012 - 2016, provides a solemn backdrop to false and 
deceitful emissions data amid an era of already low public trust in business (Edelman Trust Barometer, 2018).

In the past few decades there have been other automotive crises, such as those involving the 1973 Ford Pinto, 2010 Toyotas, and the 2018 Tesla autopilot crisis. The 1973 Ford Pinto crisis was one of the most extreme cases. The Ford Pinto engineering design had the gas tank located in the rear of the vehicle. When a Ford Pinto was rear-ended by another vehicle, the cars exploded into flames. To win back its customers, Ford had to abide by strict protocols from a legal standpoint before moving forward with winning back its consumers (Judkins, 1989).

Another major crisis happened in 2010 with Toyota Aygo, iQ, Yaris, Auris, Corolla, Verso, Avensis and RAV4 models. All of these models were affected by a gas-pedal issue, where the pedal would become stationary in one speed. Toyota created an "open letter" ad to publicize immediately to the public about the crisis (Linebaugh, 2010). One of Toyota's key marketing strategies was to personally call every consumer harmed by the crisis, and replace or fix the damaged gas-pedal. Although this process was time consuming and hurt its overall sales, Toyota was more concerned about redress for its loyal customers (Linebaugh, 2010).

Tesla Inc. is an American multinational corporation that specializes in electric vehicles, energy storage and innovative ideas to progress into the automotive future. In 2018 , the company was spiraling downhill with problems in the autopilot software, production goals and even financial challenges (Comcowich, 2018). The public relations team became the heart of the brand's problem when poor communication strategies led to unfavorable publicity. The CEO, Elon Musk, broke three major public relations rules: 1) name-calling to the press, 2) refusing to answer factual questions, and 3) improper responses/no response to deaths from Tesla car accidents (Comcowich, 2018). 
When facing a crisis within an international corporation, communications is key to recovery. "An important aspect of crisis communication is to minimize the damage to the reputation of the organization" (Lee, 2016). A New York Times article included an interview with a Michigan Volkswagen dealer who expressed concern about how they could increase sales again after the emissions crisis. In October 2016 dealership figures showed Volkswagen sales increasing by $12 \%$ from a year earlier but had still not leveled to what they were before the emissions crisis in 2015 (Boudette, 2017). The article states, "Although its United States sales are rising again, Volkswagen is still working through the impact of the diesel scandal. It has agreed to pay $\$ 22$ billion in settlements and fines in connection with the matter, including $\$ 4.3$ billion to settle a case that was brought by the Justice Department. It also agreed to compensate American customers and buy back or fix the diesel models equipped with the illegal software" (Boudette, 2017, p. 2).

In previous research people have studied consumer behavior, crisis communication, and marketing strategies in the automotive industry. The effectiveness of studying consumer behavior through their demographics, psychographics, and geographies helps researchers better identify purchasing decisions in the automotive industry. That said, analyzing corporate messaging behavior before, during, and after a crisis and corresponding sales could also provide insights. This study adds to this body of research by analyzing how Volkswagen responded to its crisis by examining its U.S. communications responses in its advertising and formal corporate messaging. Sales during this timeframe also will be explored, as will how well the company's actions conform to crisis communications responses as outlined in public relations scholarship. Such an examination may provide insights for future crisis responders and researchers, particularly those within the automotive industry. 


\subsection{Literature Review}

To provide background and context to the study, this literature review pulls from brand building, consumer advertising, and marketing literature related to the automotive industry, and then examines applicable crisis communication literature.

\subsection{Brand Building}

This section reviews elements and strategies that help safe or rebuild brands. It will touch on brand awareness, identity, image and perceptions.

\subsubsection{Building a Community: BRAND}

A brand is a name, term, desired symbol or feature that distinguishes a product or service from all others. It is an overarching identity, placement, and service to a product(s) that creates trust and liability between product and consumers. "When creating a brand, marketers teach consumers what to expect" (Smith, 2012, p. 41). For example, Verizon's slogan promotes its cell phone company has the 'best service and coverage.'. Therefore, when potential customers think of which cellphone to purchase, they will remember that Verizon has the best coverage. To have a strong and compelling brand voice with relevant identity to customers enhances the business's ability to attract customers and earn a profit. To build a brand's reputation and outlook to consumers, it's important to consider the following elements (Smith, 2012, p. 43):

Positioning: This component controls how customers perceive a brand. It's the attributes' values and customer benefits to which you wish to draw attention; the ones your customer will receive and/or experience.

Brand Identity: Begins by positioning the brand's main components in the right light to its audiences, who will interpret the brand in a positive or negative way. 
The Image: Create a story for the brand. Position the identity of the brand that relates to its audience and resonates with their values and lifestyle.

Build a Brand with People Unaware of your Community: This approach will help with brand awareness and extend its target market. Divide your potential customers into groups based on similar characteristics, needs, and behaviors.

Change Existing Perceptions: Most difficult to change because people have already positioned the brand in their thoughts. Changing perceptions requires money, time and significant effort (rebranding).

Reinforce Existing Perceptions: If existing attributes, characteristics, and values of the brand already provide a positive outlook to consumers, you should keep reinforcing the message.

Building a brand takes time, money and effort. The first step is understanding what influences the audience's purchasing decision and turn each customer into an advocate for the brand (Smith, 2012).

\subsubsection{When Good Brands Go BAD}

Building a brand image and identity takes years to establish with consumers, and in today's fast-paced technological society, brand managers must remain vigilant toward change. Toyota, General Motors, Sears and Kmart are big brand names that have lost some of their economic luster, with Kmart and Sears closing after decades of brand building and recognition (Linton, 2013). Just why and how does a good brand go bad?

Linton (2013) says there are four elements that may contribute to such downturns:

1. Taking Customers for Granted

2. Minimizing Competition

3. Ego 


\section{Loss of Objectivity}

When coming to a conclusion that your brand may be declining in purchasing popularity, Linton recommends acknowledging the data, conducting research about the brand, researching the competition and related suppliers, and strategizing new ideas for the marketplace (Linton, 2013).

\subsection{Consumer Behavior and Advertising}

This section reviews attitudes and behavior toward automobile purchasing, consumer opinion toward vehicle features and automotive marketing and communication strategies in the industry.

\subsubsection{Consumer Purchasing Decisions}

Consumer behavior is a study of how individual customers, groups or organizations select, buy, use, and dispose ideas, goods, and services to satisfy their needs and wants. In the automotive industry, consumer behavior focuses on consumer awareness, interaction, and purchasing decisions. In a previous study conducted by (Scholz, 2015), which they compared psychological factors of fuel efficient vehicles that explain intended versus actual car purchase behavior. Psychological factors include attitudinal factors, beliefs and motives toward purchasing a fuel-efficient vehicle. Therefore, the study compares environmental behaviors, impacts, and overall outcomes. For example, some consumers base environmental impacts on absolute fuel consumption and carbon dioxide emissions, while others base the impact on fuel consumption and empty vehicle weight. This study by (Scholz, 2015) used a two-wave survey method, which was distributed to 5,890 random households in June 2005. The survey questionnaire asked about participants' demographics, their current vehicle data or information (e.g., size, weight, fuel consumption, emissions) and used five-point Likert scales to collect psychological variables (e.g., problem awareness, attitudes, motives, personal norm). In an effort to find purchasing behavior correlating with fuel consumption, the results of this study 
found that fuel consumption falls under a personal norm. A personal norm is an expectation that a person holds for themselves meaning the person believes they should consider fuel consumption important because it's a "society norm." In contrast, the attitudinal aspects of less power and, smaller sized vehicles (which makes the vehicle more fuel efficient) was not considered in participants' answers. However, the surveys were only distributed to Switzerland households, which it is also is the wealthiest country in the world (Scholz, 2015). Therefore, Switzerland's economy can afford vehicles regardless of the size, weight, and fuel consumption. Still, this study demonstrated customer behavior toward purchasing a vehicle, in addition to comparing and contrasting functions of the vehicles to psychological variables.

\subsubsection{Consumer Behavior}

Consumer behavior toward safer car purchasing decisions were studied in Malaysia by Kassim, Isa, Ahmad, Osman, \& Arokiasamy (2016) through a questionnaire about safety features. Previous studies have collected similar data toward purchasing decisions within the automobile industry, but this study has updated and provided new data that had yet to be observed and calculated. Technological advancements in the automotive industry are rising, and the study investigates consumer awareness of safety features and the outcome of purchasing decisions (Kassim, et. al, 2016). The second and subsequent reference was to evaluate consumers' behavior toward car purchasing with respect to safety, and to investigate consumers' awareness of NCAP (New Car Assessment Program). Respondents were asked about their demographic profiles, knowledge toward NCAP and to rate the importance of vehicle features through a three-point Likert Scale. The top three most important factors to potential buyers included price (27\%), followed by safety (19\%), and then fuel economy (17\%). This study discovered safety is one of the most important factors to consumers (i.e., people are spending 
extra for vehicles with better safety features), and respondents considered price before safety (Kassim et al., 2016). This article also suggests, "Improvement can be made of the questionnaire by including an element of consumers' willingness to pay (WTP) focusing on more advanced vehicle safety technologies (VSTs) such as autonomous emergency braking (AEB), lane departure warning (LDW), lane keep assist (LKA), blind spot technology (BST), etc.” (Kassim, et al., 2016, p. 363). Therefore, price and vehicle safety may matter more to consumers then emissions or company integrity.

\subsubsection{Customer Segmentation}

Customer segmentation can be utilized by companies to group its consumer population into similar characteristic categories that identify the differences to develop effective marketing strategies. A group of automotive informational managers (Tsai, Ya-Han $\mathrm{Hu}$, and $\mathrm{Yu}-\mathrm{Hsin} \mathrm{Lu}$, 2015) investigated customer segmentation issues and strategies for a Taiwan automobile dealership to improve its growth in loyal consumers. This study used a two-way clustering technique by first collecting customer records from the company's database and then applying data preprocessing (Tsai, 2015). Therefore, the study took a more scientific, quantitative approach to determine different segmenting marketing strategies for automotive dealerships, incorporations of factor analysis, and a Principal Component Analysis (PCA) to filter out the unrepresentative information for this study.

The study suggests customized marketing strategies and personalized services that are designed for each customer in hopes to improve overall consumer satisfaction and loyalty. The clustering methods produced four different customer groups to verify the results (Tsai, 2015, p. 72):

Loyal: This group has the highest level of customer satisfaction and the lowest compensation 
times and complaints. The average time interval for regular service indicates a high frequency of transactions. However, the revenue contribution is lower than for Very Important Persons (VIP) and potential customers. Therefore, customers in this group have a positive valuation for the dealer, and their loyalty is high because of their high level of satisfaction.

Potential: These customers have the second highest satisfaction rating, and their revenue contribution is just lower than VIP customers. Although they have a higher frequency of compensation, they are satisfied with the services provided by the dealer.

VIP: The revenue contribution of this group is the highest, but their satisfaction is second to last. Consequently, the frequency of compensation is high. These consumers are critical, requiring a high level of service from the dealer.

Churn: The level of customer satisfaction and revenue contribution from this group is the lowest, and the frequency of complaints is the highest. These customers have the highest average period since the last transaction and do not enter into transactions with the dealer after the end of the warranty period

The groups categorize the levels of satisfaction, service revenue, service interval, frequency of transaction and compensation. When gathering the results, the study suggests the following segmentation guidelines to increase the satisfaction of customers; 1) providing generous gestures and promotional items during vehicle maintenance visits for loyal customers, 2) designating a specific technician to provide maintenance services for potential customers, 3 ) enhancing the quality of service for VIP customers and 4) improving relationships with churn customers (Tsai, 2015). 


\subsubsection{Marketing Gurus Know Their Target Audience}

The article from the Advertising Magazine wrote a column about marketers understanding their target audience and don’t perceive those people as natural consumers. Marketing a vehicle to the target audience is quite simple in the automotive industry. "Car ads are about power, luxury, status, freedom, adventure, making your neighbor feel inadequate and dazzling attractive members of whichever gender catches your fancy" (Gibson, 2013, p. 64). All aspects of an advertisement are the first steps to luring in a consumer such as scenery and landscape, slick vehicle design, background music, an attractive person piloting the vehicle, features displayed, and the power of the vehicle shown going down the road.

For a pre-geriatric audience, they are attracted to large, moderately expensive vehicles, shown out in the wilderness, with a sleek industrial design and a young, beautiful driver in her evening dress (Gibson, 2013, p. 64). For the youthful but optimistically employed buyers they are attracted to smaller vehicles that can zip through downtown city traffic. They enjoy putting the power to the test on long roadways, having a hip mid 20's person driving down an open road playing jazz music and driving endlessly into the sun. Lastly, is the mid-life crisis audience which stretches from nearly married to almost retired ages. This audience is more difficult to sell anything to because they are aware of specific features, design, color, and size of vehicles they prefer. These advertisements may leave information out to let the audience become interested first in the style and design. Once interested on the external features, the audience is persuaded to come into the dealership to discuss personalized features for their vehicle (Gibson, 2013, p. 64). Marketers understand that commercial advertising does not sell the vehicles, the ads sell the desirable images, emotional states and social opportunities. 


\subsubsection{Volkswagen Marketing Strategy}

The Volkswagen-Voting Lottery Game was conducted by Volkswagen's in-house marketing agency in 1989. This study was a social experiment that incorporated a money value of 1 million Swiss Francs (SFr). "The Volkswagen Company of Switzerland advertised a nationwide voting on the 'democratic distribution' of 1 million SFr' (Holler, 1990, p. 625). Therefore, Volkswagen sent voting papers to 2.9 million 'Swiss people' to play a role in their "lottery game." The participants were able to vote on one out of three choices on the voting ballot. The three choices included: a) 1 million SFr. for 1-person b) 47 'VW Gold Plus Ultra' of a total value of 1 million SFr., 1 car for each winner c) 1 SFr. for 1 million persons. During the voting period Volkswagen used detailed marketing and advertising strategies that allowed them to sway the voters to choice B (Holler, 1990). The participants did not know this was a study, but the company expressed it as a game to see if Volkswagen's marketing messages were working in the company's favor. Therefore, the company did predict that participants would select choice B and results show that more than 300,000 people participated, choice A received 9\%, choice B received $89 \%$, and choice $\mathrm{C}$ received $2 \%$ (Holler, 1990). The study investigating this marketing strategy suggests that Volkswagen's marketing strategy influenced a monopoly interest-group. The company was able to provide an incentive (monopoly) to enrich a group that leaned toward the desired choice (interest group). In addition, the voters were informed by Volkswagen supervisors of the winning solution, not actual winning. In conclusion, this marketing strategy displays the biasedness and acts of a pseudo voting campaign with evidence of interest groups strongly supporting the manipulated choice (Holler, 1990). Although this study is dated, it offers an excellent review about marketing strategies influencing consumers' behaviors and decisions. 


\subsubsection{Automotive Advertising}

Air pollution plays a large role in the automotive industry because the vehicles we drive are the number one pollutant that distributes carbon dioxide and other greenhouse gases into the atmosphere (Scopa, Scapellato, Perissinotto, Trevisan, Carrieri, \& Bartolucci, 2016). This study evaluated information about carbon dioxide emissions and fuel consumption in automotive advertisements. In the United States, Japan and Europe, regulations exist to help preserve clean air and the health of their citizens. Therefore, all promotional materials must: a) be easy to read and less prominent than the main information provided, b) be easy to understand even on superficial reading; c) contain the official fuel consumption of all models presented in the brochure (Scopa, et al., 2016). This study examined 902 vehicle advertisements in a monthly Italian car magazine that stretched over a nine-year period. The study was searching for information and measurable data that discussed fuel consumption, carbon dioxide, and other greenhouse gases within the vehicle advertisement they were observing. Between the years 2005 - 2009 this study examined all 60 issues of magazines published each month. Then it collected 60 more issues from the second half of 2014 which made the study's overall N=902 ads. Once the results were gathered, it compared the magazine advertisements before the regulations and the advertisements after the regulations were put in place. The automotive advertisement analysis showed an increase in emissions information from 2005 to 2014 issues, and in 2014, $98 \%$ of the required information was displayed in ads (Scopa et al., 2016).

Having these regulations allows potential car buyers the ability to make accurate choices based on the upfront information given in these advertisements. Previous studies confirm that price, comfort, size, fuel consumption, and reliability are the most popular factors during the decision-making process (Government of United Kingdom of Great Britain. Department for 
Transport, DfT, 2004). Although environmental issues seem to play a small part in the decisionmaking process, it remains important to display the information in promotional items and advertisements for the company's compliance and consumers' information.

\subsubsection{Detroit in Car Advertising}

In 2008 the automotive industry bailout was a contested political issue which presented dilemma: Should this American industry be saved by the citizen's tax dollars? The Chrysler marketing team made the decision to reestablish the character of its car company and give personality and emotional elements to its brand (Crowley, 2013). Leader of the marketing team Olivier Francois stated in Advertising Age: "The Detroit story mirrored the story of many industrial cities around the country, with economic struggle. Pennsylvania, Ohio, Indiana... they were waiting for a story like this to be told" (Crowley, 2013, p. 145). The Chrysler team created its first ad for the 2011 Super Bowl, the "Born of Fire" commercial. These advertisements were daring, fierce, and creative in which the ad told a deeper story to attract consumers. From marketing experience, Francois felt the consumers of the iconic brand need that deep connection that justifies choices and by defining the product, it helps consumers define themselves and their needs and wants. The "Born of Fire" commercial ad was centered around redefining the city of Detroit and explaining the economic impact automotive industries can give back to its cities. The commercial reveals images of Detroit's empty buildings and burnt down houses, shows hardworking citizens and inspirational athletes, and it also shows a celebrity, Eminem, who was born and raised in Detroit. The advertisement also provides instrumental background music of the song "Lose Yourself" by Eminem and he narrates: "This is the Motor City, and this is what we do" (Crowley, 2013, p. 145). The marketing strategy of this advertisement was not only to reposition the brand, but to refine Chrysler's corporate culture. Chrysler now positions its 
messages and strategies around creating stories and developing personal connections between the brand and consumer (Crowley, 2013).

\subsection{7 "Do Good” Business}

This study by (Fowler, 2018) is about blockchain technology which is an encouraging tool for delivering the level of accountability that is necessary in modern-day companies. The blockchain's purpose is to provide an effective disclosure method of certifying the supply chains in businesses that fulfill standards of social and environmental responsibility. The Volkswagen emissions scandal spent millions of dollars on advertising its environmental benefits with segmenting to an environmentally conscious target audience. "The emissions scandal is an example of 'greenwashing' which represents the information asymmetry present in product markets that involve claims of social and environment responsibility in a company's production practices" (Fowler, 2018, p. 881). The government, investors and consumers expect responsible production practices from companies which include meeting the standards of social and environmental responsibility, and in the past few decades responsible production processes grew substantially. Therefore, a new corporation was established for this specific purpose called public benefit corporations (PBCs). The PBC does not perform tasks such as a "watchdog" or an investigator, but if a company wants to consider additional shareholders, morals or missions, the PBC will investigate the investment value and approve or deny depending on the social and environmental capabilities of the company (Fowler, 2018). "As the consumer market for sustainably and responsibly sourced products and services and the investor market for shares in companies that engage in these responsible practices continue to expand, the stakes grow higher for interested parties to be able to verify that these business practices are as responsible as purported" (Fowler, 2018, p. 890). 


\subsubsection{Auto Sales Downshift}

This report comes from the Chicago Fed Letter in 2017 that examines the nation's economic growth that is forecasted to be near its long-term average in 2017 with a strong anticipation for a spike in growth in 2018. The letter interviews General Motors economic and industry forecaster David Teolis, about U.S. total vehicle sales and market value (Strauss, 2017). Teolis expected a small decrease in new vehicle sales in 2016 because a long-term historical trend from previous reports. However, interest rates, gas prices, and household annual income potentially offsets the theory of increase or decrease in the future market. When discussing the conditions of fuel efficiency and emissions, the question arose about the impacts of federal and state regulations on the U.S. economy (Strauss, 2017). Teolis said the result will decrease new vehicle sales and have a negative impact on auto industry employment. Few positive impacts would stem through innovative progressions such as automated engine start-stop systems, he said. Furthermore, this report demonstrates that regulations and economic impacts influence the automotive market success (Strauss, 2017).

\subsection{Crisis and Communication Strategies}

This section reviews apologetic, crisis and communication strategies in the automotive industry (i.e. Situational Crisis Communication Theory and the Communicative Response Model).

\subsubsection{Situational Crisis Communication Theory}

This section will discuss the importance of marketing and communication strategies in the automobile industry, and crisis communication theories that help inform marketing strategies. Situational Crisis Communication Theory (SCCT) proposes that crisis managers should match strategic crisis responses to the level of crisis responsibility and reputational threat posed by a crisis (Coombs, 2016). Coombs uses a meta-analysis to help express SCCT and to argue how 
further research can improve crisis outcomes. Coombs touches on the rebound effect and the significance of communicating to the public immediately after a crisis is publicized.

Unfortunately, a crisis is difficult to manage because there are no right answers. For example, if you report too late, the public may think the company has something to hide. Although the public may overlook an apology speech, it is crucial to still provide a public hearing for the personal and emotional affect. In contrast, it's always important to follow every step when dealing with a crisis situation. Coombs warns crisis managers that it's more vital to tell you what not to say rather than what to say. If crisis managers did not review what not to say, there is room for more controversy if the company makes a communicative mistake.

\subsubsection{Measuring Internal Crisis Communication}

Communication in the workplace is just as important as communication to customers. By taking a qualitative approach and developing semi-structured in-depth interviews with a sample of 12 company employees in Nigeria, Adamu, Mohamad, \& Abdul Rahman (2018) were able to indicate the quality of communication between management and employees. Before gathering information about internal communication at the electric distribution company, the researchers first has to understand the internal-organizational relationships and processes. Therefore, the study used two stages: 1) identify the domain of the construct and 2) generate sample items which capture the domain that has been identified (Adamu, 2018). Once the interviews were completed and analyzed, the researchers were able to establish 15 filtered items to measure the internal crisis communication. The employees expressed that the company should let the key stakeholders be involved in crisis management through two-way communication between management and the employees and that should be regulatory meetings for everyone to stay upto-date. Employees also believed the company response should be quick and complaints handled 
in an appropriate manner. The results of this study support Coombs' SCCT tenets internal crisis communication as well as SCCT. The participants were able to show the researchers that the quality of internal communication was proficient in their company and that it's important (Adamu, 2018).

\subsubsection{Apologies}

From prior research the 'Politeness Theory,' Beniot's 'Theory of Image Restoration Strategies,' and Coombs's Situational Crisis Communication Theory contribute to bad news and crisis communication situations (Janssen, 2013). As Coombs (2016) suggests in the Situational Crisis Communication Theory (SCCT), sometimes you need to be warned on what not to say rather than what to say. "Possibly the effects of apologies diminish when repeated over and over again" (Janssen, 2013, p. 263). Researchers who had been studying apology communication for ten years decided to use their prior experiments that observed bad news and crisis communication, then relate them to a real-world scenario. The 'Politeness Theory' accounts for the redressing of affronts to a person's 'face' by face-threatening acts. Therefore, the redressing and repeating factor uses more words than necessary to obtain goals. For example, if there is a recall on a vehicle function the customer is forced to have a negative face reaction because they have to bring their vehicle into the car facilities. The 'Theory of Image Restoration Strategies considers the nature of attacks or complaints that prompt such responses or instigate a crisis. The five image restoration strategies include denial, evading, reducing, corrective action and mortification (Janssen, 2013). To restore the positive reputation of a company, the strategies listed above can provide guidance on different types of image restoration methods. "These three theories explain how two or more parties need to communicate strategically in order to maintain 
their relationship or restore the relationship whenever necessary, whether this is in the build-up to, or after a face-threatening act or situation crisis" (Janssen, 2013, p. 262).

\subsubsection{Overview of Challenges Facing Collective Apologies}

Another Coombs' study (2013) provides an overview of challenges when facing collective apologies and discusses the types of crises, the level and value of apologies, and the crisis response strategies. The three crises that produce strong attributions of crisis responsibility are human-error accidents, human-error product harm, and organizational misdeeds (Coombs, 2013). A crisis is stated as negative news, which is why managers and employees worry about stakeholders (Coombs, 2013). Stakeholders represent the party who has interest in a business and contributes to the businesses finances and resources. When facing a crisis, the company needs to decide what level of apology to issue. When dealing with major crises, it's important to keep the duration period of media coverage to the lowest level (Coombs, 2013). "Greater amounts of media coverage over a long period of time presents a greater threat to the organization's reputation because of the negative stimuli it presents to stakeholders" (Coombs, 2013, p. 233). Moreover, the SCCT suggests that modifying information, expressing concern, and accepting the crisis will enhance the audience's response. Therefore, the proper dynamic of a response strategy should follow these stages: crisis (damage), apology (positive action), and repair (feel better). The key to a successful apology is the positive response that companies receive from the audience (Coombs, 2013). In contrast, if there is no apology, then that will increase the damage and create anger, negative word-of-mouth, intensify reputational damage, and decrease sales. The study states, "There is sufficient evidence from previous experimental research in corporate crisis communication to conclude that both full and partial apologies have a level of value to a crisis response" (Coombs, 2013, p. 239). Though apologies are expected in 
these circumstances, the type of crisis, level of validity, and audience can further determine the response strategy.

\subsubsection{Crisis Situations, Communication Strategies, and Media Coverage}

One multi-case study revisits the Communicative Response Model to focus on the relationships between crisis situations, crisis response strategies, and media coverage. The topic is political crises and how crisis managers respond to unethical behavior that is presented in media coverage (Huang, 2006). By using a multi-case study and a content analysis method to compare data to the theoretical model, the study helped determine how organizations and political figures use communication to protect their images during a crisis. Four political figures' crises were examined in news coverage and compared to one another. When collecting the information, the study analyzed and categorized the four political figures' crises from the types of response path, communication responses, and compared it to the Communicative Response Model.

The four types of response paths developed by Bradford and Garrett (1995) include the following:

Denials: Statements that deny the occurrence of the questionable event or that deny that the accused organization is the cause of the event.

Excuses: Statements that argue that the accused organization should not be held responsible for the occurrence and/or impact of the questionable event because certain factors limited the organization's control of the occurrence and/or impact of the event.

Justifications: Statements that argue that although the accused organization is responsible for the questionable event, the standards being used by the accusers to evaluate the impact of the questionable event are inappropriate. 
Concessions: Statements that agree that the questionable event did occur, that the accused organization caused the event, that the accused organization had control of the occurrence and/or impact of the event, and that the evaluative standards being used by the accusers are appropriate. Next, the four types of crisis situations corresponding to the four communication responses include (Bradford, J. L., \& Garrett, D. E., 1995):

Commission situation: No evidence of corporate commission.

Control situation: Evidence of corporate commission, but no evidence of corporate control.

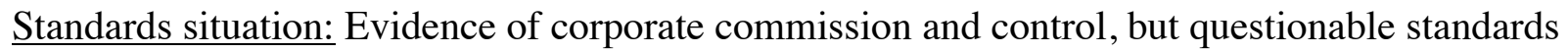
of assessment.

Agreement situation: Evidence of corporate commission and control, and appropriate standards of assessment.

After analyzing and comparing data, the study found additional evidence to support the Communicative Response Model by how crisis communication strategies (CCS) connects with media coverage (Huang, 2006). The separate or combined uses of CCS and justification as an effective strategy shows that in a commission situation, the combination of using denial and justification would exercise the most positive outcome. Moreover, in a standards situation, justification is the strongest predictor of positive media coverage, followed by concession (Huang, 2006). The findings shown in this small study revealed that a combination of crisis communication strategies was the most effective strategy to employ in these political crises. Therefore, the CCS model could be extrapolated to examine corporate crisis response messages.

\subsubsection{Crisis Communication Strategies}

A recent study Sojung (2017) wanted to "explore the effectiveness of crisis communication strategies as a function of relationships among key components (i.e., company 
and crisis)" (p. 1086). Over 133 undergraduates at The University of Texas at Austin participated in a web-based experiment, and through behavioral, attitudinal and expressional responses, the researchers were able to find an underlying mechanism of consumer response to crisis communication strategies. Although apologizing is still a viable strategy, it can sometimes result in miscommunication, undesired expenses and give the consumers the impression the crisis is attributable to the brand (Sojung, 2017). Therefore, the study found the significance of a company establishing consistent corporate associations with image management, which can provide positive audience interaction. During a company crisis it's crucial to develop an apology strategy as well as reiterate the company image to focus the audience's mind on the purpose and mission of the company instead of solely on the crisis situation.

This thesis will add to the crisis communication literature by examining if and how Volkswagen's key messages in commercial ad campaigns, individual vehicle commercials, and print ads to its United States audience changed - if at all--after the emissions scandal, whether specific crisis response strategies were employed, and how U.S. sales changed or not during the same period. Annual reports, press releases and letters to the company's shareholders will also be examined. Specifically, this study aims to answer the research questions below (Section 3.0) 


\subsection{Research Questions}

\section{PAID MEDIA}

RQ1: What crisis communication strategies, if any, did Volkswagen appear to use before, during and after the time of this emissions scandal?

RQ1a: Is there evidence of SCCT communication strategies that Volkswagen appeared to use in the print and video advertisements during the emissions scandal?

RQ1b: Is there evidence of Bradford and Garrett's communicative response model paths used in the print or video advertisements during Volkswagen's messaging?

RQ2: Did Volkswagen sales fall, rise or remain the same during the time period this study is investigating $(2015-2018)$ ?

RQ2a: If they changed, how and to what degree did it change?

\section{OWNED MEDIA}

RQ3: Did Volkswagen's CEO discuss the emissions scandal in the "Letter to Shareholders" in the annual reports?

RQ3a: If so, what years did the CEO discuss the scandal and what were his key messages?

RQ3b: If so, did he appear to use any of the crisis communication strategies noted above (i.e., SCCT and/or Bradford \& Garrett Communicative Response Model)? 
RQ4: Did Volkswagen's CEO/spokesperson mention the emissions crisis directly through corporate press releases?

RQ4a: If so, what were his key messages?

RQ4b: If so, did he appear to use any of the crisis communication strategies noted above?

* Note: this study will examine press releases issued by the company, not the news (earned) coverage that resulted. 


\subsection{Methods}

This section will discuss the research design, area of study, populations, samples, data collection, and coding scheme.

\subsection{Research Design}

This study will use content analysis to investigate Volkswagen's U.S. messaging strategies through the course of the emissions scandal. A content analysis is a method of quantitatively analyzing communication messages such as texts, visuals or audio (Zhou, \& Sloan, 2015). Therefore, this research method will help determine if the communication to the public changed within the U.S. advertisements Volkswagen aired before, during and after the crisis. Because this study is investigating a sample of Volkswagen's paid and owned media only (commercial campaigns, individual vehicle ads, and print campaigns, shareholder letters, press releases) a coding sheet will be developed to code each commercial advertisement before, during and after $(2015$ - 2018) the emissions crisis. This study also examines evidence of SSCT and communicative response model frames in the VW annual reports, letter to shareholders and press releases and examines sales data in years 2015, 2016, and 2017 from the annual reports.

The resources used to obtain VW sales data include the VW official media site that holds all press releases and earned news media, the Volkswagen Group website to track annual sales figures and letter to shareholders from 2015 - 2017, and Statista Online Database to show yearly sales records between VW and other vehicle brands each year it has been documented. The VW sales data will only observe years $2015-2017$ considering there is no annual report yet available for the year 2018. 


\subsection{Populations \& Samples}

The sample viewed all available advertisements between years $2015-2018$. The 12 advertisements for this study came from three different mediums: print, individual vehicle broadcast, and campaign broadcast ads (2015 - 2018). The table shown below displays the title of advertisements, the medium, where it can be retrieved, and the date it was published.

\begin{tabular}{|c|c|c|c|}
\hline Title & Medium & Retrieved $\nabla$ & Year $\nabla$ \\
\hline The Right Tools & Print Ad & CampaignLive & Jul-15 \\
\hline Think Small & Print Ad & AnciraVolkswagen & Jul-16 \\
\hline Pencil & Print Ad & AdWorld & Jun-17 \\
\hline A Bit Too Risky-Bird & Print Ad & AdWorld & Jun-18 \\
\hline Boss & Commercial Campaign & CampaignLive & Feb-15 \\
\hline Then. Now. Always. & Commercial Campaign & CampaignLive & Feb-16 \\
\hline Rain & Commercial Campaign & VW YouTube & Oct-17 \\
\hline Born Confident & Commercial Campaign & CampaignLive & Jan-18 \\
\hline TDI Diesel & Individual Car Ad & VW YouTube & Sep-15 \\
\hline Passat AllTrack & Individual Car Ad & VW YouTube & Jan-16 \\
\hline Atlas & Individual Car Ad & Vw YouTube & Mar-17 \\
\hline Tiguan & Individual Car Ad & vw YouTube & Jan-18 \\
\hline
\end{tabular}

Table 1: Table of Population Under Study. K. M. Plute, 2018.

Next, sampling units are communication messages that will be gathered for the findings of this content analysis (Zhou \& Sloan, 2015). Therefore, the sampling units for this study will be individual commercial ads that were published/broadcast between $2015-2018$. These sampling units were retrieved from campaignlive.com, Ads of the World, and Volkswagen's official YouTube channel. 
Campaign Live is an Untied States platform that displays creative advertising pieces.

"It's a place to showcase inspiring work, debate issues, share opinions, learn from the best in the business" (About Campaign, n.d.). Ads of the World is an online platform that collects ads across any type of medium promoting any type of brand, company, or product. The online site wants visitors to "be inspired by global work across diverse industries and to be able to stay updated on the top and most recent creative ads" (Volkswagen Ads, n.d.). This creates separate pages for industries such as Volkswagen. YouTube is an online media platform that believes in giving everyone a voice and allowing them to see the world. This gives companies the opportunity to create their own YouTube channel to provide viewers with the opportunity to subscribe and to keep updated on the most recent posts. Volkswagen's YouTube channel has multiple different playlists that include vehicle information and features, garage sound, VW auto shows, VW service and parts, VW television commercials and more. Although this study examines research on three different platforms, each one still holds sufficient credibility to use for researching commercial and print advertisements because the platforms credit the company, Volkswagen.

\subsection{Instrument for Data Collection}

The researcher designed a coding sheets using an emergent coding scheme (Martinelli \& Mucchiaroni, 2007) as the data collection instrument for this study. The 12 Volkswagen print and commercial advertisements, 10 press releases and 3 shareholder letters from 2015 to 2018 was coded by the researcher, a West Virginia University graduate student. Another graduate student will be trained to allow for intercoder reliability testing. The additional graduate student is also pursuing a Masters at West Virginia University and was selected because of their field of study and motivation to research. Both researchers working on this content analysis pretested 
VW material in 2012 and 2013 in September 2018 and provided feedback about the coding sheet. This helped the researcher find any poor/confusing questions, which could comprise the research study of accurate results. The coding sheets questions (See 6.0 Appendix A) aimed to find alterations of messaging strategies for each year (2015 - 2018) by investigating each ad, press release and shareholder letter

Measuring the intercoder reliability extends to working on coding sheets independently on the same messages to reach the same conclusions. A percentage agreement of $0.70 \%$ using Scott's Pi is typically required as a minimal level of acceptable agreement (Zhou \& Sloan, 2015). A pretest using Volkswagen ads, press releases and a shareholder letter that will not be part of the study will be conducted first to test the coding sheet and to ensure the coders have a similar understanding of the research under study. If an adequate intercoder reliability is found, (Scott's Pi or Krippendorf's alpha)—meaning a desired $.80 \%$ in the pretest—then the study coding will commence. The study coding will commence on September 3, 2018 and close on October 1, 2018.

Each question has been pretested with only one question answered differently between the two coders. Question 5) "If so, how many images appear during the duration of the advertisement" in the ad coding sheet asked the coders to select one numeric answer. There was confusion between coders which convinced the researcher to make question five an open-ended answer. With a $98 \%$ intercoder agreement and adjusting the one question found coding sheets to be suitable and comprehensive for accurate data collection. Although a percentage agreement allows for some random agreement, unlike intercoder calculations such as Krippendorf's alpha or Scott's Pi, the agreement was strong enough to be deemed reliable to continue. 
For accurate results, a codebook was developed to provide proper instructions, guidance, and question definitions for each coder to follow a consistent method. (See Appendix 10.0 A) The coders will answer every coding question with a number to provide comparative data. The data was used to examine any the changes in messaging tactics, images, and the overall concept/theme each advertisement campaign promoting. It was able to identify if VW utilized the Communicative Response Model or SCCT strategies. Each print, individual commercial, and campaign ads typically has one overarching theme that's supposed to affect viewers in an emotional and/or attitudinal way. Therefore, the content analysis coding sheets will help identify the results of research questions (RQ1), (RQ1a) and (RQ1b) on the matter of finding evidence of Volkswagen's use of specific communication and marketing strategies in advertisements to help gain consumers after the emissions crisis.

The coding sheets will also recognize the type of strategies used and whether the strategies leaned toward Combs SCCT or Bradford and Garrett's Response Path theory. Reviewing Volkswagen's annual reports and shareholder letters between 2015 to 2018 will help answer research questions (RQ2), (RQ2a), (RQ3), (RQ3a), and (RQ3b). The annual reports show the exact numbers for Volkswagen's annual sales data and the CEO's letter to shareholders is located at the beginning of every report. The last research questions, (RQ4), (RQ4a), and (RQ4b) will be answered by coding Volkswagen's press releases and public broadcasts retrieved from credible online news sources.

\subsection{Coding Scheme}

Because our interest focuses on the frequency with which strategies are used throughout the years of study, this content analysis coding sheet allows for recording the number of times changes in visuals, audio, or text in each advertisement are observed. When analyzing the data 
found in Volkswagen's commercial advertisements, the data will be categorized into three groups: "Coombs SCCT", "B \& G Response Paths", or "No Strategies Have Been Identified".

\section{Coombs SCCT:}

Situational Crisis Communication Theory (SCCT) proposes that crisis managers should match strategic crisis responses to the level of crisis responsibility and reputational threat posed by a crisis (Coombs, 2016). This theory explores the avenues with which to communicate to the public after a crisis. For this coding scheme it pays attention to apologetic and upfront crisis responses to the audience. Therefore, questions entered into this section seeks audio, visuals, text or overarching theme used to arouse emotional intentions to the audience.

\section{B \& G Communicative Response Model Paths:}

Bradford and Garrett (1995) proposed four distinct communicative responses in their model, which emphasized that the audience tends to focus on negative actions compared to positive actions. Each response path labeled in section 2.2.4 on pages $16-17$ explains the strategies in fine detail (i.e. Denial, Excuses, Justifications, Concessions). This model is used in this study to identify which element, if any, is used in Volkswagen's ads or external messaging.

\section{No Strategies Have Been Identified}

This category will identify that Volkswagen does not show any identity to crisis communication strategies and/or related emotional appeal. This study would bypass Coombs SCCT and Communicative Response Model Paths, meaning no overt crisis strategy or emotional appeal/theme was observed. 


\subsection{Validation of the Coding Sheet}

Since the population under study is messaging in the form of text, visuals and audio, there will be no human interaction during the coding process. Validating the coding sheet through pretesting other Volkswagen commercial advertisements, allows the actual research study to be carried out. This study includes intercoder reliability (ICR) because it's required in any content analysis for assuring validity when more than one coder is involved in data analysis (Zhou \& Sloan, 2015). Furthermore, the two coders will not speak of individual advertisements, data or results until all sheets are final and collected. Once the coding is finished, the findings will then be entered into Statistical Package for the Social Sciences (SPSS) a software platform to run the analyses (Zhou \& Sloan, 2015). Finally, using the results from SPSS can answer this study's research questions regarding frequencies and any changes over time.

The main purpose of this content analysis design sets out to test whether Volkswagen's print and commercial advertisement and public messaging tactics changed between 2015 to 2018. The findings will appear in the thesis results section.

\subsection{Findings/Results}

This study analyzed available Volkswagen commercial and print advertisements, press releases and shareholder letters from the time the emissions crisis broke in 2015 to mid-2018. By using a content analysis method, it provided insight into Volkswagen's use of crisis strategies (SCCT and CRM) in their communication to the public, their consumers and the company's shareholders. Below are the findings for each research question in this study. 
(RQ 1) What crisis communication strategies, if any, did Volkswagen appear to use before, during and after the time of this emissions scandal?

(RQ1a) Is there evidence of SCCT communication strategies that Volkswagen appeared to use in the print and video advertisements during the emissions scandal?

(RQ1b) Is there evidence of Bradford and Garrett's communicative response model paths used in the print or video advertisements during Volkswagen's messaging?

Advertisements, press releases and shareholder letters were analyzed to determine if Volkswagen used SCCT and CRM crisis communication strategies. There were 12 print and video advertisements analyzed in this study. Of the $12 \mathrm{ads}$, nine (75\%) showed no signs of crisis communication strategies, while three ads (25\%) presented indications of CRM and/or SCCT during 2015 - 2018. As shown in Tables 2 and 3 below, these three advertisements were "Old Wives Talk Dirty," "BOSS" and "Born Confident," and SSCT strategies were used in all three; while CRM strategies were found in only one. (Intercoder reliability was $98 \%$.)

\begin{tabular}{|c|c|c|c|c|c|}
\hline \multicolumn{5}{|c|}{ Ads Using Coomb's SCCT } & \multirow[b]{2}{*}{ Strategy } \\
\hline & & Yes & No & Name of Ad & \\
\hline & Air Date & & & & \\
\hline & $2 / 16 / 15$ & 0 & 1 & "BOSS" & Physcial Tactics to Keep Customers Happy \\
\hline & $7 / 9 / 15$ & 0 & 1 & "The Right Tools" & N/A \\
\hline & $8 / 21 / 15$ & 1 & 0 & "Old Wives Talk Dirty" & Word Selection \\
\hline & $1 / 14 / 16$ & 0 & 1 & "Volkswagen Passat Alltrack Advert" & N/A \\
\hline & $2 / 8 / 16$ & 0 & 1 & "Then. Always. Now" & N/A \\
\hline & $7 / 19 / 16$ & 0 & 1 & "Volkswagen, Think Small" & N/A \\
\hline & $3 / 22 / 17$ & 1 & 0 & "Love Bug" & N/A \\
\hline & $6 / 1 / 17$ & 0 & 1 & "This Pencil is Definitely Worth Writing About" & N/A \\
\hline & $10 / 17 / 17$ & 0 & 1 & "People First" & N/A \\
\hline & $12 / 27 / 27$ & 1 & 0 & "Born Confident" & Confidence in Performane \\
\hline & $1 / 13 / 18$ & 0 & 1 & "Meteor" & N/A \\
\hline & $4 / 11 / 18$ & 0 & 1 & Volkswagen, A Little Too Risky" & N/A \\
\hline
\end{tabular}

Table 2: SCCT Strategies in VW Ads, 2015-2018. 


\begin{tabular}{|c|c|c|c|c|c|}
\hline \multicolumn{5}{|c|}{ Ads Using Bradford \& Garrett's CRM } & \multirow[b]{2}{*}{ Strategy } \\
\hline & & Yes & No & Name of Ad & \\
\hline & Air Date & & & & \\
\hline & $2 / 16 / 15$ & 0 & 1 & "BOSS" & N/A \\
\hline & $7 / 9 / 15$ & 0 & 1 & "The Right Tools" & $N / A$ \\
\hline & $8 / 21 / 15$ & 1 & 0 & "Old Wives Talk Dirty" & Justifications, Commission Situation \\
\hline & $1 / 14 / 16$ & 0 & 1 & "Volkswagen Passat Alltrack Advert" & N/A \\
\hline & $2 / 8 / 16$ & 0 & 1 & "Then. Always. Now" & N/A \\
\hline & $7 / 19 / 16$ & 0 & 1 & "Volkswagen, Think Small" & N/A \\
\hline & $3 / 22 / 17$ & 0 & 1 & "Love Bug" & N/A \\
\hline & $6 / 1 / 17$ & 0 & 1 & "This Pencil is Definitely Worth Writing About" & N/A \\
\hline & $10 / 17 / 17$ & 0 & 1 & "People First" & N/A \\
\hline & $12 / 27 / 27$ & 0 & 1 & "Born Confident" & N/A \\
\hline & $1 / 13 / 18$ & 0 & 1 & "Meteor" & N/A \\
\hline & $4 / 11 / 18$ & 0 & 1 & "Volkswagen, A Little Too Risky" & N/A \\
\hline Total & & 1 & 11 & 12 & \\
\hline
\end{tabular}

Table 3: CRM Strategies in VW Ads, 2015-2018.

Next, the three VW shareholder letters (2015 - 2017; note: 2018 was yet to be released during the period of this study) were analyzed. SCCT and CRM communication strategies were found in two of the three shareholder letters $(66 \%$, with $100 \%$ intercoder agreement $)$. Ten press releases issued during 2015 - 2018 also were analyzed. This analysis showed Volkswagen used these crisis communication strategies in $80 \%$ of the press releases observed in this study; intercoder agreement was $96 \%$.

(RQ2) Did Volkswagen sales fall, rise or remain the same during the time period this study is investigating $(2015-2018) ?$

(RQ2a) If they changed, how and to what degree did they change?

In September 2015, Volkswagen's diesel emissions crisis erupted which forced that year's annual report to include a section explaining this matter. In "The Emissions Issue" section, it stated the allegations made against the company and explained how Volkswagen issued an extensive investigation to clarify the "irregularities" (Volkswagen, 2015, p. 49). "The 
announcement of the 'Defeat Device' scandal shaved $\$ 20$ billion off of the company's market cap and the stock dropped nearly 30\% virtually overnight" (Stash, 2016).

Thus, in 2015 it seems the crisis led to sharp falls in overall sales

(Volkswagen, 2015). Figures $1 \& 2$

shows the highlighted figures of overall vehicle sales in $2014-2015$ and Graph 1 displays VW stock progress in 2015 2016.

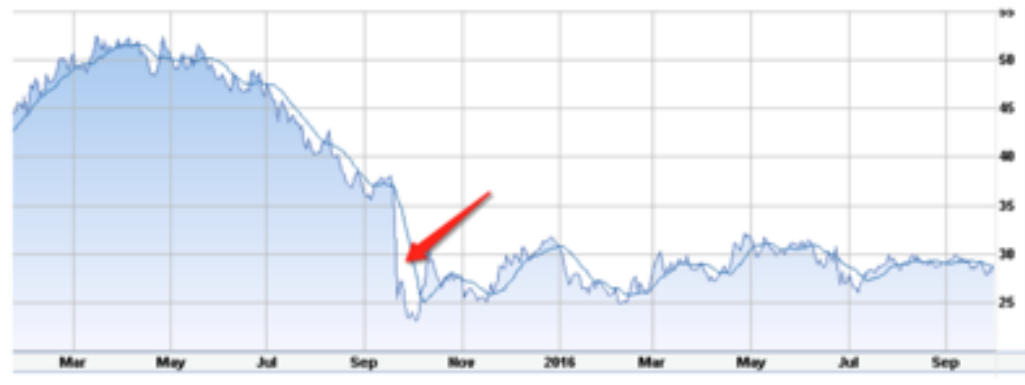

Graph 1: VW Stock Results 2015 - 2016. Adapted from "VW Is Said to Cheat on Diesel Emissions," by C.

Davenport, 2015, Online

Retrieved November 11, 2018, from https:/www.nytimes.com/2015/09/19/business/volkswag en-is-ordered-to-recall-nearly-500000-vehicles-over-
Volume data ${ }^{1}$

Vehicle sales (units)

Production (units)

Employees at Dec. 31

\begin{tabular}{|c|c|c|}
\hline $10,009,605$ & $10,217,003$ & -2.0 \\
\hline $10,017,191$ & $10,212,562$ & -1.9 \\
\hline 610,076 & 592,586 & +3.0 \\
\hline
\end{tabular}

Figure 1: 2014-2015 VW Vehicle Sales. Adapted from “2015 VW Annual Report," by Volkswagen Group, Online Retrieved October 2018 from https://www.volkswagenag.com/en/InvestorRelations/news-andpublications/Annual_Reports.html

\begin{tabular}{|c|c|c|c|}
\hline Financial data (HGB), $\mathbf{\epsilon}$ million & 2015 & 2014 & $\mathbf{x}$ \\
\hline Sales & 73,510 & 68,971 & +6.6 \\
\hline Net loss/net income for the year & $-5,515$ & 2,476 & $\mathrm{x}$ \\
\hline \multicolumn{4}{|l|}{ Dividends (C) } \\
\hline per ordinary share & 0.11 & 4.80 & \\
\hline per preferred share & 0.17 & 4.86 & \\
\hline
\end{tabular}

Figure 2: Figure of VW Sales. Adapted from "2015 VW Annual Report," by Volkswagen Group, Online Retrieved October 2018 from https://www.volkswagenag.com/en/InvestorRelations/news-andpublications/Annual_Reports.html 
In 2016, Volkswagen’ s annual report slogan was "Redefining Mobility," which is appropriate considering the crisis the year before. The results show an increase over the previous year's sales of 10,009,605 (units) (see Figure 3).

Volume data $^{1}$
Vehicle sales (units)
Production (units)
Employees at Dec. 31
Figure 3: 2015-2016 VW Vehicle Sales. Adapted from "2016 V
Volkswagen Group, Online Retrieved October 2018 from
https://www.volkswagenag.com/en/InvestorRelations/news-and-
publications/Annual_Reports.html

In Volkswagen's 2017 annual report, the overall vehicle sales increased from 10,391 (in thousands) in 2016 to 10,777 (in thousands) in 2017 (see Figure 4).

\begin{tabular}{|c|c|c|c|}
\hline & 2017 & 2016 & $\mathbf{x}$ \\
\hline \multicolumn{4}{|l|}{ Volume Data ${ }^{1}$ in thousands } \\
\hline Deliveries to customers (units) & 10,741 & 10,297 & +4.3 \\
\hline Vehicle sales (units) & 10,777 & 10,391 & +3.7 \\
\hline Production (units) & 10,875 & 10,405 & +4.5 \\
\hline Employees at Dec. 31 & 642.3 & 626.7 & +2.5 \\
\hline
\end{tabular}

Figure 4: 2016-2017 VW Vehicle Sales. Adapted from "2017 VW Annual Report," by Volkswagen Group, Online Retrieved October 2018 from https://www.volkswagenag.com/en/InvestorRelations/news-andpublications/Annual_Reports.html

Therefore, these statistics display that Volkswagen's vehicle industry is at an overall upswing following the emissions scandal, but when the emissions scandal happened, there was a decrease in the global sales that year. 
(RQ3) Did Volkswagen's CEO discuss the emissions scandal in the "Letter to Shareholders" in the annual reports?

(RQ3a) If so, what years did the CEO discuss the scandal and what were his key messages?

(RQ3b) If so, did he appear to use any of the crisis communication strategies noted above (i.e., SCCT and/or Bradford \& Garrett Communicative Response Model)?

Two of the three shareholder letters $(2015$ - 2016) discussed the emissions crisis. Throughout each letter, the CEO and the company stressed the importance of "rebuilding trust" and "overcoming" the crisis. In the findings, the two shareholder letters noted above used SCCT and CRM crisis communication strategies to address the situation to its investors (see Table 4).

\begin{tabular}{|c|c|c|c|c|c|}
\hline \multicolumn{6}{|c|}{ Mention of Crisis in Shareholder Letter } \\
\hline & Frequency & Percent & Years & Use of SCCT & CRM \\
\hline Yes & 2 & $66.7 \%$ & 2015,2016 & Yes; Apologetic, Future Strategies & Yes; Justifications \\
\hline No & 1 & $33.3 \%$ & 2017 & No; N/A & No; N/A \\
\hline Unsure/Don'tKnow & 0 & 0 & N/A & & \\
\hline Total & 3 & $100 \%$ & N/A & & \\
\hline
\end{tabular}

Table 4: Crisis Communication Strategies in Shareholder Letters, 2015-2017. 
(RQ4) Did Volkswagen's CEO/spokesperson mention the emissions crisis directly through corporate press releases?

(RQ4a) If so, what were his key messages?

(RQ4b) If so, did he appear to use any of the crisis communication strategies noted above?

Yes. Volkswagen's communications team mentioned the crisis in eight of ten press releases during 2015 - 2018 (see Table 5). Intercoder reliability was 96\%.

\begin{tabular}{|c|r|r|r|r|r|}
\hline \multicolumn{5}{|c|}{ If Yes, What Years? } \\
\hline & 0 & 2015 & 2016 & 2017 & Total \\
\hline Mention of Crisis in PR & & & & & \\
\hline Yes & 0 & 2 & 2 & 4 & 8 \\
\hline No & 2 & 0 & 0 & 0 & 2 \\
\hline Unsure/Don't know & 0 & 0 & 0 & 0 & 0 \\
\hline Total & 2 & 2 & 2 & 4 & 10 \\
\hline
\end{tabular}

Table 5: Emissions Crisis Mentions in VW Press Releases, 2015-2017.

Volkswagen emphasized its desire to rebuild an honest relationship with consumers. For example, a 2015 release said, "This Group and its brands stand for sustainability, for responsibility, for credibility. At the moment, much of that seems to have been deeply shaken. But together with you, I am determined to prove that our values remain our guide. And that Volkswagen, that each one of us, deserves the trust of people everywhere" (MÜLLER, 2015). Also, Volkswagen's CEO states:

We appreciate the constructive engagement of all the parties, and are very grateful to our customers for their continued patience as the settlement approval process moves ahead. We know that we still have a great deal of work to do to earn back the trust of the American people. We are focused on resolving the outstanding issues and building a better company that can shape the future of 
integrated, sustainable mobility for our customers (VW Reaches Settlement, 2016).

In addition, $80 \%(\mathrm{~N}=8)$ of the ten press releases analyzed incorporated crisis communication strategies. One press release showed no signs of crisis strategies, while coders were unsure about the other (see Table 6). (Intercoder reliability was 100\%.)

\begin{tabular}{|l|r|r|l|l|}
\hline \multicolumn{5}{|c|}{ CEO Using Comm Strategies in Press Releases } \\
\hline & Frequency & Percent & Use of SCCT & CRM \\
\hline Yes & 8 & $80 \%$ & Yes; Apologetic, Future Strategies & Yes; Justifications \\
\hline No & 1 & $10 \%$ & No; N/A & No; N/A \\
\hline Unsure/Don'tKnow & 1 & $10 \%$ & No; N/A & No; N/A \\
\hline Total & 10 & $100 \%$ & & \\
\hline
\end{tabular}

Table 6: Observed Communication Strategies in VW Press Releases, 2015-2018.

\subsection{Discussion \& Conclusions}

The purpose of this study is to build on crisis communication literature by examining if Volkswagen included crisis communication strategies in its commercial ad campaigns, individual vehicle commercials, and print ads in the United States after the emissions scandal. The analysis also observed annual reports, press releases, and letters to the company's shareholders to identify specific SCCT and CRM crisis response strategies and examined U.S. sales fluctuations during this time frame.

After carefully analyzing and coding each advertisement, press release and shareholder letter, the results show Volkswagen's crisis communications team seems to have bypassed apologizing directly to its consumers via advertisements, perhaps in an attempt to move past the crisis and not remind people of it. However, the company did offer in-depth explanations and 
apologies to its shareholders through its Security and Exchange Commission-required annual reports and to the media through its news releases.

The crisis lasted for months until Volkswagen finally had to admit its culpability in September 2015, which would have given the communications team time to come up with a crisis action plan (Davenport, 2015). However, this study found that the company's advertisements post-crisis showed scant signs of SCCT and CRM crisis communication strategies, but that the company did employ these crisis communication strategies through press releases and shareholder letters, in which they apologized and emphasized a desire to rebuild trust and loyalty.

By examining different media that target specific audiences, this study indicated that communications strategies varied, depending on the audience. This study found that Volkswagen used SCCT and CRM crisis communication strategies in most press releases and annual report shareholder letters. SCCT was likely found the most frequent in Volkswagen shareholder letters because its investors expect extensive information on crisis issues, an apology and future strategies for positive actions. The press releases showed more CRM strategies, such as justifications and commission situations likely because the VW spokesperson works to portray the issue and the brand in a positive light. Volkswagen was able to use justification responses in press releases to barely touch on the issue and focus more on its brand image and future goals. In contrast, Volkswagen failed to utilize crisis strategies toward its consumers (people who purchase its vehicles) through advertisements.

In this study's literature review (section 2.3.3 Overview of Challenges Facing Collective Apologies), the importance of translating crisis information to stakeholders, investors or 
shareholders is discussed. Shareholders represent a party, company or person that owns at least one share of a company's stock. Because shareholders are a company's owner, they reap the benefits of the company's successes in the form of increased stock valuation. Therefore, when Volkswagen's crisis erupted the company had to respond. It was no surprise to find that VW used SCCT strategies in its communication to shareholders. Even though the price of stocks was declining, VW was determined to keep its shareholders loyal. The SCCT suggests that modifying information, expressing concern, and accepting the crisis will enhance the audience's response. When examining each annual report shareholder letter, the key messages expressed concern toward the emissions crisis, discussed rebuilding its reliable brand and looked toward a positive future.

When reviewing the study's results, there is more usage of the overall SCCT over CRM. However, the study still found some CRM communication strategies in press releases and shareholder letters. The literature review (section 2.3.4 Crisis Situations, Communication Strategies, and Media Coverage) that discussed CRM compared four types of response paths to four communication responses. This study found that Volkswagen used two of those response paths: justifications and commission situation in its communication to its audience. Justifications are statements that argue that although the accused organization is responsible for the questionable event, the standards being used by the accusers to evaluate the impact of the questionable event are inappropriate. Commission situation is a response path that shows no evidence of corporate commission.

Volkswagen chose to discuss future actions with the brand and company as part of its communication strategies. This strategy steers the audience to think of a different topic, to think of the future and what is to come rather than the problems of the past. The literature review 
(section 2.1.0 Building a Community: BRAND) also discusses the importance of building a company's brand reputation and outlook to consumers by following these six elements: brand identity, brand image, building brand awareness, changing negative perceptions and reinforcing positive ones. In the material reviewed for this study, Volkswagen kept reminding its consumers, shareholders and the media of its bright future and discussed rebuilding its brand in multiple press releases.

This study examined the use of SCCT and CRM crisis communication strategies in different media (print and broadcast commercial, shareholder letters, press releases) from the time the diesel emissions scandal broke in 2015 until mid-2018. The study found little to no crisis communication strategy being used for consumers through print and broadcast advertisements, but found robust crisis communication strategies in shareholder letters and press releases to the media. This finding makes intuitive sense in that shareholders and media could potentially wield more immediate damage to corporate finances and reputation.

\subsection{Limitations to this Study}

As with all research, this study has several limitations. For example, the small sample size of 12 VW advertisements, 10 press releases and 3 shareholder letters is limited to years $2015-2018$ because the emissions scandal occurred more than halfway through 2015 and this study was begun in mid-2018. In addition, the study uses three types of media: advertisements, press releases and shareholder letters. Therefore, each form of communication is different, so direct comparisons can be problematic. Also, Volkswagen and media coverage of the issue could be at odds, and the key messages VW issues to consumers, media, and stockholders likely were not the messages the media used in its coverage of the scandal. Additional content analysis of actual media coverage of the crisis could make a beneficial second phase of this research project. Also, 
this study did not explore whether Volkswagen's agency of record (AOR) was consistent throughout the crisis or if the AOR changed following the crisis (if the AOR did change, it would be interesting to know if the agency served ties with the company owing to ethical conflicts). In this study it is unknown whether paid media (advertising) budgets increased, decreased or remained the same post-scandal.

In addition, after the emissions scandal in 2015, VW pulled multiple advertisements from the Internet. Well-known ad coverage websites wrote online articles about the VW emissions scandal and referenced many videos from YouTube and Facebook, which are now unavailable to the public. Therefore, some of the most compelling emissions-related ads being run pre-crisis may not have been available for this study. In addition, nontraditional media (e.g. Facebook, Instagram, Twitter) were not examined and may have included crisis communication strategies not observed in traditional advertising.

Although there are multiple studies about the VW diesel emissions scandal, no known study had yet studied the crisis communication strategies of the company. Therefore, this limits this study's prior knowledge and foundation upon which to build, but makes it potentially valuable by helping to fill this research gap.

Of course, any seeming correlation between the crisis and sales does not imply causation, as there are many factors involved in consumers' auto purchasing decisions, and this study investigates only the content of documents available to the public, such as the VW press releases and annual reports. This examination eliminates such information as internal corporate messages during the scandal, investigation documentation, and crisis communication public relations firms or advertising agencies of record ideas and tactics, which could help provide additional case study insights and conclusions. 


\subsection{Future Research}

The automotive industry will always encounter recalls on parts and vehicles and will need crisis communication strategies to translate these mistakes to the public and investors. Typical company crisis goals are to apologize, fix the error, and move forward, focusing on the growth of the company's future. Because of the strict timeline associated with this study, the research conducted was limited. However, future research could repeat this study observing the VW European media, use focus groups, customer attitude surveys, and explore the Elaboration Likelihood Model or situational theory of publics through experiments to build upon and extrapolate this study's findings. For example, through focus groups one could collect public opinion to see how much people know and remember of the VW emissions crisis, gauge how much they care about the crisis, and their opinion toward VW advertisements and press releases in terms of trust, credibility and reputation.

The Elaboration Likelihood Model (ELM) seeks to examine how humans process stimuli differently and the outcomes of these processes on changing attitudes and consequently behavior (Geddes, 2016). Elaboration refers to the level of effort an audience has to use in order to process the message translated, remember it and be able to interpret it to someone else. The ELM advances when a persuader (communications/spokesperson) presents information to an audience, a level of "elaboration" results. There are two types of processing routes: central and peripheral. Central processing is a high-level elaboration which means the audience has a strong sense of motivation to listen and learn about the messages being presented. Peripheral processing is a low-level elaboration which means the audience is not examining the message as effectively and distractions can get in the way of concentration (Geddes, 2016). The ELM can contribute to this study's future research by examining consumer "elaboration" toward the VW emissions crisis 
and responses or could observe elaboration (mental processing) of diesel-related emissions issue changes as awareness of tightened regulations and climate change becomes more salient to consumers. Lastly, experiments could help gauge which crisis communication strategies "resonate" so that greater elaboration occurs, and which strategies result in a more direct, low level message processing.

Such active and passive information seeking can be explored as dependent variables and level of audience involvement as an independent variable per Grunig and Hunt's (1984) situational theory of publics. Therefore, the segmented audience messaging found in different mediums in this study, could be further explored using their concepts of latent and active audiences.

Lastly, future researchers could explore the crisis communication strategies used by other automotive companies to seek out possible response patterns, and identify or look for industry best practice approaches. 


\subsection{Appendix A}

\section{Plute Thesis Codebook}

\section{Volkswagen Advertisement Coding Instructions:}

This codebook is designed to help in the process of coding personal ads. Each element is defined based on its use in this study. You are to refer to these definitions and only these definitions while coding your ads. You may know of other definitions of these words, but those do not apply to this study. In addition, you are to code the ads based on the instructions that follow. You may have previous experience in research or coding but because each study is different, you are to code only according to these instructions.

Instructions:

This is a study of how Volkswagen, an automotive company, may have strategically altered its advertising messages through different mediums (print, broadcast, and campaign) throughout the years to persuade and promote its brand to the public. Therefore, this study is observing 12 different print, commercial, and campaign ads from 2015 to 2018 to identify any changes before, during or after the Volkswagen emissions crisis. The job as a coder for this study is to watch each ad campaign once without looking at this coding sheet and then watch it a second time and identify images, emotions, words, or phrases you observe during the second viewing. After identifying each of these items, the coder will proceed to answer every question in numerical order on the coding sheet for each advertisement.

In section one of this codebook you will find a list of words and definitions. These words are the strategies of this study, the definitions are the applications of the strategies in this study. The coder's first duty is to become familiar with the questions and its definitions. Read through the list a few times, ask questions if you do not understand the definition. Remember that these may not be the definitions that you are most familiar with, so pay close attention.

After some definitions there will be specific instructions for coding that question. If no specific instructions are offered, please follow the basic instructions found here. Begin with the dated ads 2015 and proceed to the latest ads, 2018. 
Basic instructions:

1. Please provide the date of coding, name of coder and ad campaign identification number at the top of each coding sheet.

2. Watch or observe each VW print, commercial, or campaign advertisement completely without viewing the coding sheet

3. Re-watch or observe each VW print, commercial, or campaign advertisement a second time with observing the coding sheet. Pay close attention to detail and answer each coding question in numerical order. As you find strategies or appeals, mark them down on the codesheet assigned to that advertisement. If the commercial or campaign advertisements move too fast, please proceed to pause the video while answering each question carefully.

Section 1: Strategies \& Definitions

\section{Question 6}

VW Logo - Volkswagen (VW) logo is a symbol or other design adopted by an organization (which is Volkswagen) to identify its products, uniform, vehicles, etc.

Volkswagen Vehicle - Any model of Volkswagen's vehicles that are displayed somewhere within the commercial (outside, in the showroom, driving, etc.)

Crowd of People - (More than three) or (multitudes) of people in camera view can be considered a crowd/ large number of people for this commercial.

Customers - ONLY people shown at VW dealerships, buying a VW vehicle, trading in a VW vehicle, selling a VW vehicle.

Landscape - The vehicle driving along beautiful sceneries, off-roading to camping areas, showing a lot of nature scenes.

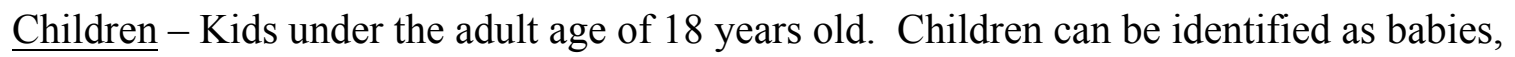
toddlers or teenagers.

\section{Question 10}

Protesting - Crowd of people declaring (something) firmly and emphatically in the face of stated or implied doubt or in response to an accusation (angry emotions).

Chanting - A crowd of people proudly cheering for something they believe in (happy, emotional, joyful) 
Singing - Crowd of people making musical sounds with the voice, especially words that set a tune.

Laughing - A family, group of friends, a couple, or a crowd making the spontaneous sounds and movements of the face and body that are the instinctive expressions of lively amusement and sometimes also of contempt or derision.

Volunteering - A crowd of people freely offering to do something for the better good.

Performing - A crowd of people, a vehicle, one person, a children carrying out, accomplishing, or fulfilling (an action, task, or function).

\section{Question 17}

Happy - Showing pleasure or contentment.

$\underline{\text { Sad }}$ - Expressing or showing sorrow: unhappy.

Excited - Very enthusiastic and eager.

Angry - Having a strong feeling of or showing annoyance, displeasure, or hostility; full of anger.

Concerned - Worried, troubled or anxious

Relaxed - Free from tension and anxiety; at ease.

Irritated - Showing or feeling slight anger; annoyed.

Emotional - Having feeling that are easily excited, intensified, and openly displayed.

Unaffected - No effects or changes in feelings.

\section{Questions 19 \& 20}

Situational Crisis Communication Theory (SCCT): Proposes crisis managers should match strategic crisis responses to the level of crisis responsibility and reputational threat posed by a crisis. The theory touches on the rebound effect and the significance of communicating to the public immediately after the crisis is publicized. It also warns crisis managers that it's more vital to tell you what not to say rather than what to say. Therefore, pay attention to the emotional and 
attitudinal appeals to the audience that stem from audio, visuals, text or an overarching theme to arouse emotional.

\section{Questions $21 \& 22$}

Please chose one of the four elements of response paths developed by Bradford and Garrett:

Denials: Statements that deny the occurrence of the questionable event or that deny that the accused organization is the cause of the event.

Excuses: Statements that argue that the accused organization should not be held responsible for the occurrence and/or impact of the questionable event because certain factors limited the organization's control of the occurrence and/or impact of the event.

Justifications: Statements that argue that although the accused organization is responsible for the questionable event, the standards being used by the accusers to evaluate the impact of the questionable event are inappropriate.

Concessions: Statements that agree that the questionable event did occur, that the accused organization caused the event, that the accused organization had control of the occurrence and/or impact of the event, and that the evaluative standards being used by the accusers are appropriate.

Then chose one of the four elements of crisis situations:

Commission situation: No evidence of corporate commission (i.e. acknowledging guilt).

Control situation: Evidence of corporate commission, but no evidence of corporate control.

Standards situation: Evidence of corporate commission and control, but questionable standards of assessment.

Agreement situation: Evidence of corporate commission and control, and appropriate standards of assessment. 
In conclusion, the coder is to code only the ads assigned to you. All ads should refer to Volkswagen. If you find an ad containing other variables that are not noted in the coding sheet, leave comments at the end of the sheet for each advertisement. 
9.1 Ad Coding Sheet

Date of Coding:

Name of Coder:

Sampling Information ID\#:

Commercial Aired: Month:

Day: Year:

1. Duration of unit?

[1] 3 minutes

[2] 2 minutes

[3] 1 minute

[4] 30 seconds

[5] Other (How Long?)

[6] None of the Above

2. Media type examined:

[1] Print [2] Web-based [3] Other

3. Is there music/audio in the commercial?

[1] Yes

[2] No

4. Are there multiple images during the advertisement?

[1] Yes

[2] No

5. If so, how many images appear during the duration of advertisement?

6. Does the commercial show any of the following images (refer to codebook for the following definitions)? (Can Circle Multiple Answers)

[1] VW Logo [2] Volkswagen Vehicle [3] crowd of people [4] customers [5] landscape

[6] children [7] None of the above 
7. Does the commercial seem to represent a predominant feature?

[1] Family \& Friends [2] Performance of Vehicle [3] Love for Children [4] Accomplishments

[5] None of the above

For the following questions, if they DO NOT apply to the commercial leave the question blank.

8. If the commercial shows the Volkswagen logo, how many times can you identify the logo?

Please provide number here:

9. If the commercial shows the Volkswagen vehicle, what features of the car does it display or talk about? (Can Circle Multiple Answers)

[1] price [2] fuel economy [3] safety functions [4] style, design, color

[5] maintenance/service [6] performance [7] reliability [8] vehicle size [9] comfort

10. If the commercial shows a crowd of people, what is the crowd doing (refer to codebook for the following definitions)?

[1] Protesting [2] Chanting [3] Singing [4] Laughing [5] Volunteering _6] Performing

[7] Other [8] None of the Above

11. If the commercial shows Volkswagen customers, what are they doing in the commercial?

[1] Buying a VW [2] Test driving a VW [3] Trading a VW [4] Other

[5] None of the Above

12. If the commercial shows children, do they...

[1] Grow-up in a VW [2] Dream of VW [3] Was conceived in VW [4] Sitting in VW

[5] Other [6] None of the Above

Continue to answer all the following questions: 
13. Does the advertisement mention the diesel emissions?

[1] Yes

[2] No

14. Does the advertisement mention emissions feature at all?

[1] Yes

[2] No

15. Does the advertisement mention the environment?

[1] Yes

[2] No

16. Does the advertisement mention Volkswagen sales?

[1] Yes

[2] No

17. Does the advertisement make you personally feel (Refer to the codebook for the following definitions)...

[1] happy [2] sad [3] excited [4] angry [5] concerned [6] relaxed [7] irritated

[8] emotional [9] unaffected [10] other [11] None of the Above

18. Does the advertisement mention any of these words throughout the commercial (Circle Multiple Answers)?

[1] rebuild [2] trust [3] loyalty [4] better [5] honest [6] remake [7] fix [8] together

[9] None of the Above

19. Do questions 13 - 18 follow some on Coombs' Situational Crisis Communication Theory (SCCT)?

[1] Yes

[2] No

[3] Unsure/Don't Know

20. If yes, write the question numbers that follow the SCCT:

21. Does the advertisement use the Communicative Response Model? 
[1] Yes

[2] No

[3] Unsure/Don't Know

22. If Yes, please write which two elements the advertisement follows:

23. Does the advertisement feel like it's persuading the viewer to be a loyal consumer to VW?

[1] Yes

[2] No

[3] Unsure/Don’t Know

For the following questions, if they DO NOT apply to the commercial leave the question blank.

24. If a commercial video, does the advertisement start or end with written text?

[1] Yes

[2] No

25. If yes, check whether it's at the start or finish or both

26. If yes, what does the text say?

START:

FINISH:

Continue to answer all the following questions:

27. Other Emotional Appeals that don't fit above (loaded words, taglines/slogans, semantics as text or visuals on screen)?

[1] Yes

[2] No

[3] Unsure/Don't Know

If Yes, specify 
9.2 Press Release Coding Sheet

Date of Coding:

Name of Coder:

Sampling Information ID\#:

1. Did Volkswagen's CEO mention the emissions crisis directly through press releases?

[1] Yes

[2] No

[3] Unsure/Don't Know

2. If yes, please list all years:

3. Did the VW CEO express the company's key messages and/or mission statement in press releases?

[1] Yes

[2] No

[3] Unsure/Don't Know

4. Did the CEO appear to use any of the crisis communication strategies noted above (i.e. SCCT and/or B \& G Communicative Response Model) in press releases?

[1] Yes

[2] No

[3] Unsure/Don't Know

5. Did the press releases state any changes and/or future strategies the company is developing to gain back its target market?

[1] Yes

[2] No

[3] Unsure/Don’t Know 
Date of Coding:

Name of Coder:

Sampling Information ID\#:

1. Did Volkswagen's CEO discuss the emissions scandal in the "Letter to Shareholders" in the annual reports?

[1] Yes

[2] No

[3] Unsure/Don't Know

2. If yes, please list all years:

3. Did the CEO discuss the scandal and/or the company's key messages to shareholders?

[1] Yes

[2] No

[3] Unsure/Don't Know

4. Did the CEO appear to use any of the crisis communication strategies noted above (i.e. SCCT and/or B \& G Communicative Response Model) when discussing to shareholders?

[1] Yes

[2] No

[3] Unsure/Don't Know

5. Does the "Letter to Shareholders" discuss future strategies and/or promotions to gain back its target market?

[1] Yes

[2] No 


\subsection{Bibliography}

(2015, October). Testing Times. Nature. P. 5. Doi:10.1038/526005a.

About Campaign. (n.d.). Retrieved April 11, 2018, from https://www.campaignlive.com/about-us

Adamu, A. A., Mohamad, B. B., \& Abdul Rahman, N. B. (2018) Towards Measuring Internal Crisis Communication: A Qualitative Study. Journal of Asian Pacific Communication (John Benjamin's Publishing Co.),28(1), 107-128. Doi:10.1075/japc.0006.ada

Boudette, N. E. (2017, November 2). Volkswagen Sales Bounce Back in U.S. New York Times. p. B2.

Bovens, L. (2016). The Ethics of Dieselgate. Midwest Studies In Philosophy, 40(1), 262-283. Doi:10.1111/misp.12060

Bradford, J. L., \& Garrett, D. E. (1995). The effectiveness of corporate communicative responses to accusations of unethical behavior. Journal of Business Ethics, 14(11), 875-892.

Bradsher, K. (2014, Nov 10). No longer business as usual in china. New York Times (1923Current File) Retrieved from https://search-proquestcom.www.libproxy.wvu.edu/docview/1941544215?accountid=2837

Cedillo-Campos, M. G., \& Perez-Araos, A. (2010). Hybrid Supply Chain in Emerging Markets: The Case of the Mexican Auto Industry. South African Journal of Industrial Engineering, 21(1), 193-206.

Comcowich, W. (2018) Glean.Info. Tesla Breaks PR Rules of the Road. (accessed June 6, 2018).

Coombs, W. T. (2016). Reflections on a Meta-Analysis: Crystallizing Thinking About SCCT. Journal of Public Relations Research [serial online]. April 2016;28(2):120-122 Available from: Communication \& Mass Media Complete, Ipswich, MA. Accessed March 5, 2018.

Coombs, W.T. (2013). An Overview of Challenges Facing Collective Apologies: Their Uses in the Corporate World. At The Interface / Probing the Boundaries, 86229-247.

Crowley, K. (2013). What We Do: Detroit in Car Advertising. Journal of Mass Media Ethics, 28(2), 145-147. Doi: 10.1080/08900523.2013.784671

Davenport, C., \& Ewing, J. (2015, September 18). VW Is Said to Cheat on Diesel Emissions; U.S. to Order Big Recall. Retrieved November 11, 2018, from 
https://www.nytimes.com/2015/09/19/business/volkswagen-is-ordered-to-recall-nearly500000-vehicles-over-emissions-software.html?module=inline

Dearden, H. (2016). VW: When the 'Smoke' Clears. TCE: The Chemical Engineer no. 896: 41. Academic Search Complete, EBSCOhost (accessed March 4, 2018).

Deutsche Umwelthilfe (DUH). 2015. "Fahrverbote für Diesel-PKW in Deutschen Städten ab 2016 und Entzug der Typengenehmigung als Folge des Audi/VW-Skandals in den USA." Retrieved June 5, 2016, from <http://www.duh.de/pressemitteilung.html?\&tx_ttnews [tt_news] $=3611>$.

Fowler, M. D. (2018). Linking the Public Benefit to the Corporation: Blockchain as a Solution for Certification in an Age of "DO Good" Business. Vanderbilt Journal Of Entertainment \& Technology Law, 20(3), 881-917.

Geddes, J. (2016, October). Elaboration Likelihood Model Theory - Using ELM to Get inside the User's Mind. Retrieved October 18, 2018, from https://www.interactiondesign.org/literature/article/elaboration-likelihood-model-theory-using-elm-to-get-insidethe-user-s-mind

Gibney, A. (2018, January 26). Hard NOx. Retrieved June 6, 2018, from https: $/ /$ www.netflix.com/watch/80149533?trackId $=14277283 \&$ tctx $=0,0$, f5dccdaa-dd544799-bfb2-84175ad74e1f-11957114,

Gibson, R. (2013). Advertising. Alternatives Journal (AJ) - Canada's Environmental Voice, $39(2), 64$.

GoodCarBadCar.net. (n.d.). Leading car brands in the United States in 2016, based on vehicle sales (in units). In Statista - The Statistics Portal. Retrieved February 23, 2018, from https://www.statista.com/statistics/264362/leading-car-brands-in-the-us-based-onvehicle-sales/.

Government of United Kingdom of Great Britain. Department for Transport (DfT), 2004. Assessing the Impact of Graduated Vehicle Excise Duty-Quantitative Report. Department for Transport. Available at: 〈http://www.dft.gov.uk/rmd/ project.asp?intProjectID1/411615〉 (accessed 25.04.15.).

Grunig, J. E., \& Hunt, T. (1984). Managing public relations. New York: Holt, Rinehart and Winston.

Halliday, J. (2002). Volkswagen look to fix flat sales. Advertising Age, 73(26), 4-45.

Holler, M. J. (1990). Voting as a Marketing Strategy. Kyklos, 43(4), 625. 
Huang, Y. H., (2006). Crisis Situations, Communication Strategies, and Media Coverage. Communication Research, 33(3), 180-205. Doi:10.11177/00193651J206287077

Janssen, D. (2013). Apologies in Written Messages: What Are the Effects?. At The Interface / Probing The Boundaries, 86249-267.

Judkins, B. M. (1989). Corporate Crime Under Attack: The Ford Pinto Case and Beyond (Book). Social Forces, 67(3), 818-819.

Kassim, K. A., Isa, M. M., Ahmad, Y., Osman, I., \& Arokiasamy L. Consumer Behavior towards Safer Car Purchasing Decisions. Journal Of Engineering \& Technological Sciences [serial online]. July 2016; 48(3):359-366. Available from: Academic Search Complete, Ipswich, MA. Accessed February 20, 2018

Lee, S. Y. (2016). Weathering the crisis: Effects of stealing thunder in crisis communication. Public Relations Review, 42(2), 336-344. Doi:10.1016/j.pubrev.2016.02.005

Li, L., McMurray, A., Xue, J., Liu, Z., \& Sy, M. (2018). Industry-wide corporate fraud: The truth behind the Volkswagen scandal. Journal Of Cleaner Production, 1723167-3175. Doi:10.1016/j.jclepro.2017.11.051

Linebaugh, K. (2010, Jan 30). The toyota recall: Toyota is unable to hit the brakes on crisis. Wall Street Journal, Retrieved from https://search-proquestcom.www.libproxy.wvu.edu/docview/399149295? accountid=2837

Linton, M. (2013, June 19). When Good Brands Go Bad. Retrieved August 20, 2018, from https://www.forbes.com/2010/04/07/toyota-general-motors-branding-cmo-network-mikelinton.html\#10bfa7933f26

Martinelli, D. \& Mucchiaroni J. (2007). New Deal Public Relations: A Glimpse into FDR Press Secretary Steven Ph. Earlys Work, Public Relations Review

MATTHIAS MÜLLER: WE WILL OVERCOME THIS CRISIS. (2015, October 5). Retrieved September, 2018, from https://media.vw.com/en-us/releases/589

Old Wives Talk Dirty. (2015, September 23). Retrieved June 06, 2018, from https://www.youtube.com/watch?v=uddhe2BM8XA

Peters, A., de Haan, P., \& Scholz, R. W. (2015). Understanding Car-Buying Behavior: Psychological Determinants of Energy Efficiency and Practical Implications. International Journal of Sustainable Transportation, 9(1), 59-72. Doi:10.1080/15568318.2012.73672

Ries, T., Bersoff, D., Adkins, S., Arnstrong, C., \& Bruening, J. (2018). Edelman Trust Barometer. Global Report. doi:10.4135/9781483376493.n106 
Scopa, P., Scapellato, M. L., Perissinotto, E., Trevisan, A., Carrieri, M., \& Bartolucci, G. B. (2016). The greenhouse gas automotive advertisement study. Transport Policy, 4577-85 doi:10.1016/j.tranpol.2015.09.009

Smith, W.C., \& Ingram, R. (2012). Building a Community: BRAND. Economic Development Journal, 11(3), 41-47.

Sojung, K., Sejung Marina, C., \& Atkinson, L. (2017). Congruence Effects of Corporate Associations and Crisis Issue on Crisis Communication Strategies. Social Behavior \& Personality: An International Journal, 45(7), 1085-1098. Doi: 10.2224/sbp.6090

Special to The New York Times. (1972, Feb 28). Volkswagen discovers outlook is brightening. New York Times (1923-Current File) Retrieved from https://search-proquestcom.www.libproxy.wvu.edu/docview/119384474? accountid=2837

Stash. (2016, October 06). VW Scandal: How Has It Impacted Volkswagen's Stock? (VLKAY). Retrieved November 11, 2018, from https://www.investopedia.com/news/vw-scandalhow-has-it-impacted-volkswagens-stock-vlkay/

Strauss, W. A., \& Haasl, T. (2017). Economy to cruise near speed limit in 2017 and 2018 as auto sales down shift. Chicago Fed Letter, (381), 1-6.

Trop, J. (2014, Jan 14). Poor U.S. sales are a drag on Volkswagen's ambitions. New York Times (1923-Current File) Retrieved from https://search-proquestcom.www.libproxy.wvu.edu/docview/1941436532?accountid=2837

Tsai, C., Hu, Y., \& Lu, Y. (2015). Customer segmentation issues and strategies for an automobile dealership with two clustering techniques. Expert Systems, 32(1), 65-76 doi:10.1111/exsy.12056

Volkswagen Ads. (n.d.). Retrieved June 6, 2018, from https://www.adsoftheworld.com/taxonomy/brand/volkswagen

Volkswagen reaches settlement agreements with u.s. federal regulators, private plaintiffs and 44 u.s. states on tdi diesel engine vehicles. (2016, June 28). Retrieved September, 2018, from https://media.vw.com/en-us/releases/715

Volkswagen. (n.d.). Volkswagen's worldwide vehicle sales from 2006 to 2017 (in millions). In Statista - The Statistics Portal. Retrieved March 21, 2018, from https://www.statista.com/statistics/272049/worldwide-vehicle-sales-of-volkswagen-since$2006 /$.

Volkswagen. (2015). Moving People. Volkswagen Annual Report 2015. p. 0-23,49-58.

Volkswagen. (2016). We Are Redefining Mobility. Volkswagen Annual Report 2016. p. 0-23,5158. 
Volkswagen. (2017). Shaping the Transformation Together. Volkswagen Annual Report 2017. p. $0-23,51-58$.

Whytas, K. J. (2016). Impact of a brand crisis on nation branding: An analysis of tweets about $V W$ 's emissions crisis (Order No. 10108397). Available from ProQuest Dissertations \& Theses Global. (1793670277). Retrieved from https://search-proquestcom.www.libproxy.wvu.edu/docview/1793670277?accountid=2837

Zhou, S., \& Sloan, D. (2015) Chapter 9: Content Analysis. Research Methods in Communication. Ed. 3, p. 119-137. 
